\title{
Placental glucocorticoid receptors are not affected by maternal depression or SSRI treatment
}

\author{
Åsa Edvinsson ${ }^{\mathrm{a}, \mathrm{b}}$ (D), Angela Hoyer ${ }^{\mathrm{a}}$, Malin Hansson ${ }^{\mathrm{a}}$, Theodora Kunovac Kallak ${ }^{\mathrm{a}}$ (D), \\ Inger Sundström-Poromaa ${ }^{a}$ (D) Alkistis Skalkidou ${ }^{a}$ (D) and Susanne Lager ${ }^{a}$ (DD

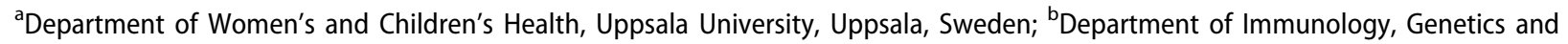 \\ Pathology, Uppsala University, Uppsala, Sweden
}

\begin{abstract}
Background: Prenatal depression is common, with an estimate that up to one in five pregnant women suffers from depressive symptoms. Maternal depression is associated with poor pregnancy outcomes such as preterm birth and low birth-weight. Such outcomes possibly affect offspring development. Previous studies suggest placental RNA levels of the glucocorticoid receptor are altered by maternal depression or anxiety; this stress may affect the placenta of male and female foetuses differently. However, it is unknown if the protein levels and activity of this receptor are additionally affected in women with depressive symptoms or being pharmacologically treated for depression.

Methods: In this study, we investigated whether the glucocorticoid receptor (NR3C1) in the placenta is affected by maternal depression and/or selective serotonin reuptake inhibitor (SSRIs) treatment. Placentas from 45 women with singleton, term pregnancies were analysed by Western blot to determine glucocorticoid receptor levels, and by DNA-binding capacity to measure glucocorticoid receptor activation.

Results: There were no differences in levels of the glucocorticoid receptor or activity between groups (control, depressive symptoms, and SSRI treatment; $n=45$ ). Similarly, there was no difference in placental glucocorticoid receptor levels or activity dependent upon foetal sex.

Conclusion: Maternal depression and SSRI treatment do not affect the glucocorticoid receptors in the placenta.
\end{abstract}

\section{ARTICLE HISTORY}

Received 21 August 2019

Revised 23 November 2019

Accepted 4 December 2019

\section{KEYWORDS}

NR3C1; pregnancy; prenatal depression; SSRI;

Western blot

\section{Introduction}

During pregnancy, women experience major physical and psychological changes which increase their risk for development of mental illness. It is estimated that approximately $10-20 \%$ of pregnant women experience depressive symptoms (1). The proportion of women suffering from major depressive disorder in pregnancy is lower, but it still affects many women, with a prevalence of about $3-5 \%(2,3)$. To manage depression, selective serotonin reuptake inhibitors (SSRIs) are commonly prescribed medications during pregnancy. In Europe, up to $4.5 \%$ of pregnant women are prescribed SSRIs (4). In the USA, it is twice as common that women use antidepressant drugs during pregnancy (5). Both maternal depression and SSRI treatment are associated with poor pregnancy outcomes (6-9).

It is common that pregnant women experience anxiety, depression, and psychosocial distress. Such distress often stimulates the hypothalamic-pituitary-adrenal (HPA) axis, resulting in release of stress hormones (for instance cortisol) (10). It has been shown that direct transfer of cortisol from the maternal circulation to the foetus across the placenta is limited (11). But cortisol can also exert its effects through the glucocorticoid receptor (NR3C1) (12), which is present in the placenta (13). Maternal stress has been shown to directly affect the placenta. For instance, increased placental RNA levels of the glucocorticoid receptor have been observed in association with maternal perceived stress or depressive symptoms (14-16). Interestingly, the effects of maternal stress may affect the placenta from female and male infants differently $(17,18)$.

Previous studies have focussed on glucocorticoid receptor mRNA levels, which may not reflect the protein amount of receptor present in the tissue. It is currently unknown if protein levels or activation of the placental glucocorticoid receptor are affected as well. Therefore, the aim of this study was to determine if maternal depression or SSRI treatment affects placental protein levels of glucocorticoid receptor.

\section{Material and methods}

\section{Study population}

Samples utilized in this study are from the Biology, Affect, Stress, Imaging, and Cognition (BASIC) cohort conducted at Uppsala University Hospital, Department of Women's and Children's Health (19). The study was approved by the 
Regional Ethical Review Board in Uppsala (Dnr 2009/171 with amendments). All participants gave informed written consent. Briefly, women who were registered for a routine ultrasound scan at Akademiska University Hospital in Uppsala around 17 weeks gestation were asked about participation in the BASIC study. From participating women, data were collected through web-based surveys, including the Edinburgh Postnatal Depression Scale (EPDS) (20), at 17 and 32 weeks gestation. A sub-set of women was invited to a visit in late pregnancy (around 38 weeks gestation) for a structured psychiatric interview (Mini International Neuropsychiatric Interview, MINI). From the BASIC cohort, 45 women with singleton pregnancies were selected for the present study. The women were divided into three groups: control, depressive symptoms, and SSRI treatment. Women in the control group had a maximum EPDS score of 9 during pregnancy and no history of psychiatric illness according to medical records $(n=17)$. The women in the depressive symptoms group had an EPDS score of 12 or greater in gestational weeks 17 and/or $32(n=14)$. Six of these women were depressed according to MINI conducted in late pregnancy. The women in the SSRI treatment group used SSRI medication during at least half of the pregnancy $(n=14)$. All the women in the SSRI treatment group had measurable blood concentrations of their prescribed SSRI at delivery (except one woman prescribed sertraline where no blood sample was available for testing). Clinical characteristics of the selected pregnancies are presented in Table 1.

\section{Tissue collection}

Placental tissue collection was carried out as soon as possible after delivery. A full-thickness biopsy was sampled from the central part of the placenta, selecting areas devoid of calcifications and infarcts. The samples were rinsed in sterile phosphate-buffered saline, frozen on dry ice within $30 \mathrm{~min}$ after delivery, and then stored at $-70^{\circ} \mathrm{C}$ until further processing. From the frozen tissue biopsies, small samples were carefully cut from the villous tissue to exclude tissue from the basal and chorionic plates.

\section{Western blot}

Placental villous tissue samples were homogenized in RIPA buffer $(25 \mathrm{mM}$ Tris- $\mathrm{HCl}$ pH 7.6, $150 \mathrm{mM} \mathrm{NaCl}, 1 \% \mathrm{NP}-40,1 \%$ sodium deoxycholate, 0.1\% SDS; cat\# 89900, Thermo Fisher Scientific) containing Halt Protease Inhibitor Cocktail (cat\# 87785, Thermo Fisher Scientific). Protein concentrations of homogenates were determined using the Bradford assay (B6919, Sigma-Aldrich, St. Louis, MO). Western blot was performed on $4-12 \%$ Bis-Tris pre-cast gels (NP0323, Thermo Fisher Scientific, Waltham, MA) and transferred onto PVDF membranes (IPFL00010, Merck Millipore, Burlington, MA). After transfer, membranes were stained for total protein with Amido Black Staining Solution (A8181, Sigma-Aldrich) and/or Ponceau S Staining Solution (P7170, Sigma-Aldrich). Total protein stains have been previously proposed as a good reference for Western blotting of placental proteins (21). Thereafter, membranes were blocked for $1 \mathrm{~h}$ at room temperature in Odyssey Blocking buffer (927-40000, LI-COR Biosciences, Lincoln, NE). After blocking, the membranes were probed with beta-actin (final concentration $0.2 \mu \mathrm{g} / \mathrm{mL}_{i}$ SC-47778, Santa Cruz Biotechnology, Dallas, TX; $1 \mathrm{~h}$ at room temperature) or glucocorticoid receptor ( $\mathrm{NR3C} 1$; final concentration $81 \mathrm{ng} / \mathrm{mL}$; ab109022, Abcam, Cambridge, UK

Table 1. Clinical characteristics.

\begin{tabular}{|c|c|c|c|}
\hline & Healthy control & Depressive symptoms & SSRI treatment \\
\hline \multicolumn{4}{|l|}{ Mother } \\
\hline$n$ & 17 & 14 & 14 \\
\hline Age at delivery (years) & $30 \pm 3$ & $31 \pm 5$ & $31 \pm 5$ \\
\hline $\mathrm{BMI}\left(\mathrm{kg} / \mathrm{m}^{2}\right)$ & $24.9(21.5-32.2)$ & $23.7(21.1-26.4)$ & $24.9(22.5-29.3)$ \\
\hline Primiparous women & $8(47 \%)$ & $6(43 \%)$ & $4(29 \%)$ \\
\hline Preeclampsia & $0(0 \%)$ & $0(0 \%)$ & $0(0 \%)$ \\
\hline Hypertension & $0(0 \%)$ & $0(0 \%)$ & $0(0 \%)$ \\
\hline Diabetes & $0(0 \%)$ & $0(0 \%)$ & $0(0 \%)$ \\
\hline Ethnicity (born in Scandinavia) & $17(100 \%)$ & $14(100 \%)$ & $14(100 \%)$ \\
\hline College/university education & $15(88 \%)$ & $10(71 \%)$ & $10(77 \%)$ \\
\hline Missing & 0 & 0 & 1 \\
\hline \multicolumn{4}{|l|}{ Mode of delivery } \\
\hline Vaginal & $13(76 \%)$ & $11(79 \%)$ & $11(79 \%)$ \\
\hline Elective CS & $1(6 \%)$ & $2(14 \%)$ & $2(14 \%)$ \\
\hline Intrapartum CS & $3(18 \%)$ & $1(7 \%)$ & $1(7 \%)$ \\
\hline EPDS, gestational week 17 & $2(1-7)$ & $13(12-16)$ & $9(5-12)$ \\
\hline Missing & 0 & 0 & 1 \\
\hline EPDS, gestational week 32 & $3(1-6)$ & $15(14-16)$ & $7(5-9)$ \\
\hline Missing & 1 & 0 & 2 \\
\hline SSRI & $0(0 \%)$ & $0(0 \%)$ & $\begin{array}{l}\text { Fluoxetine, } 5 \text { (36\%); Sertraline, } 5 \text { (36\%); } \\
\text { Citalopram, } 4(29 \%)\end{array}$ \\
\hline \multicolumn{4}{|l|}{ Newborn } \\
\hline Gestational length (days) & $281(276-288)$ & $286(280-290)$ & $277(272-280)$ \\
\hline Birth-weight (kg) & $3.76 \pm 0.68$ & $3.90 \pm 0.42$ & $3.66 \pm 0.38$ \\
\hline Sex, proportion female & $7(41 \%)$ & $7(50 \%)$ & $6(35 \%)$ \\
\hline NICU care after delivery & $0(0 \%)$ & $0(0 \%)$ & $1(7 \%)$ \\
\hline
\end{tabular}

Data are presented as mean $\pm S D$, median (IQR), or number (\%).

BMI: body mass index; CS: Caesarean section; EPDS: Edinburgh Postnatal Depression Scale; IQR: interquartile range; NICU: neonatal intensity care unit; SD: standard deviation; SSRI: selective serotonin reuptake inhibitor. 
overnight at $+4{ }^{\circ} \mathrm{C}$ ). Immunolabeling was visualized with fluorescently labelled secondary antibodies (926-68070 or 926-32211, LI-COR Biosciences) in an Odyssey Sa scanner (LICOR Biosciences). Images were analysed with ImageJ (version 1.52a). Placental levels of the glucocorticoid receptor (GR) were adjusted for total protein staining intensity (Ponceau S staining).

\section{Transcription factor activity}

Nuclei were isolated from $40 \mathrm{mg}$ of placental villous tissue using the Nuclear Extraction Kit (ab113474; Abcam). Protein concentrations of isolated nuclei were measured with the Bradford assay (Sigma-Aldrich). The DNA binding capacity of NR3C1 was determined with the Glucocorticoid Receptor Transcription Factor Assay Kit (ab207207; Abcam) using $3.9 \mu \mathrm{g}$ of nuclear extract per well. Nuclei extraction and GR transcription factor assay were performed according to the manufacturer's instructions. The GR transcription factor activity was tested in duplicate for each placenta.

\section{Statistics}

Statistical analysis was carried out using IBM SPSS Statistics, version 25. Placental glucocorticoid receptor levels and activity were tested for normality using the Shapiro-Wilk test; differences between the groups were evaluated by one-way ANOVA test, $t$ test, Kruskal-Wallis, or Mann-Whitney $U$ test as appropriate.
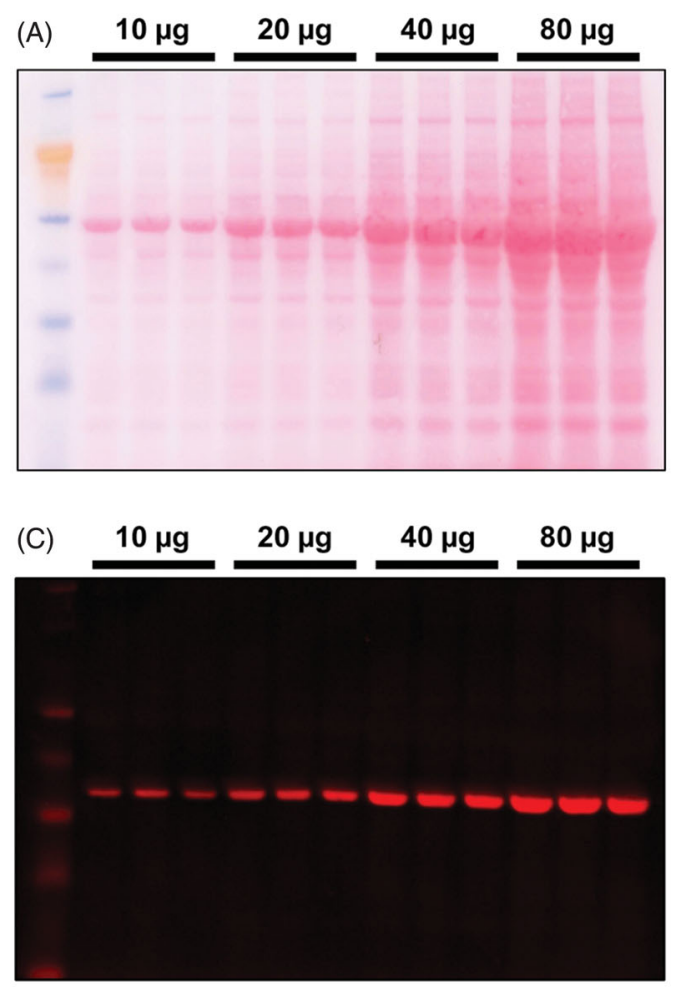

\section{Results}

\section{Western blotting loading control}

Prior to examining placental levels of the glucocorticoid receptor, three different approaches were evaluated as potential loading controls for the Western blot analysis: total protein staining by Amido Black and Ponceau S, as well as probing the membrane for beta-actin (Figure 1). Ponceau $S$ was selected as the appropriate loading control and used in subsequent experiments.

\section{Placental NR3C1 protein}

The glucocorticoid receptor was detected as a main band at approximately $100 \mathrm{kDa}$ (Figure 2(A)). In 45 placentas, levels of the glucocorticoid receptor were measured and adjusted for total protein (Ponceau S staining; Figure 2(B)). Detectable level of the glucocorticoid receptor was present in all but two samples. The results were similar when including these two samples (the value of glucocorticoid receptor level as zero) or excluding the samples completely from the analysis. When comparing placentas from healthy controls, women with depressive symptoms, and women using SSRIs during pregnancy, no difference in glucocorticoid receptor levels between the groups was observed (Figure 2(C)). Response to these stressors did not differ depending on foetal sex (Figure 2(D)). Similarly, there was no difference in glucocorticoid receptor levels when comparing placentas from female and
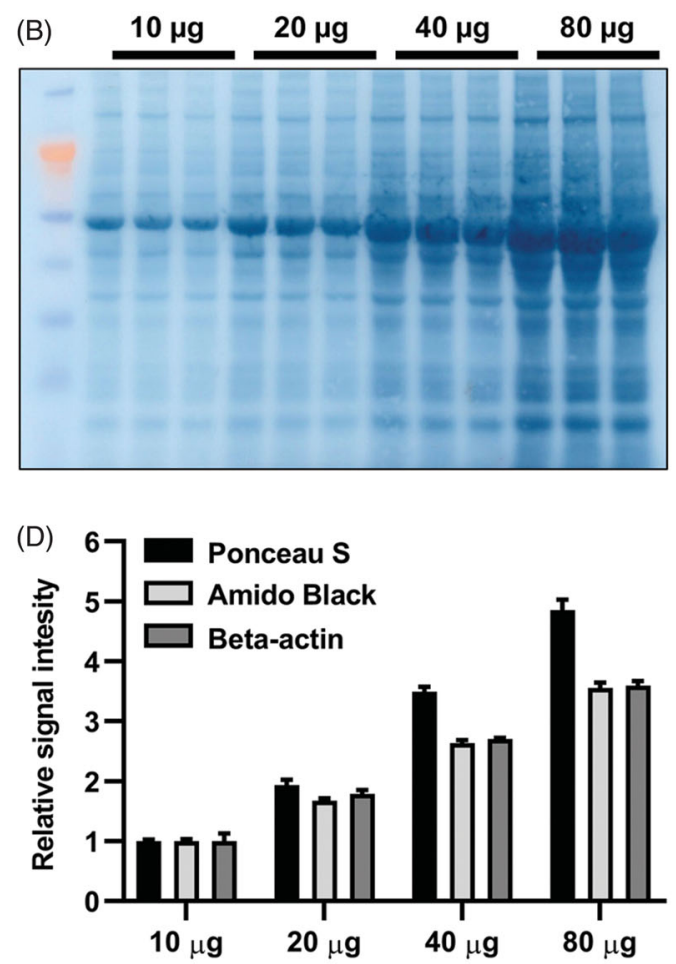

Amount of placental protein loaded

Figure 1. Western blot loading control. For evaluation of loading controls, one membrane was first stained with: (A) Ponceau S; followed by (B) Amido Black; and lastly (C) the membrane was probed for beta-actin. (D) Quantification of total protein stains and beta-actin. Far left lane contained a molecular weight marker. Ponceau $S$ displayed values closest to the expected doubling and was used as loading control for subsequent experiments. The mean values of the $10 \mu \mathrm{g}$ protein loading signals were assigned a value of 1 . Data are presented as mean $\pm \mathrm{SEM}$. 


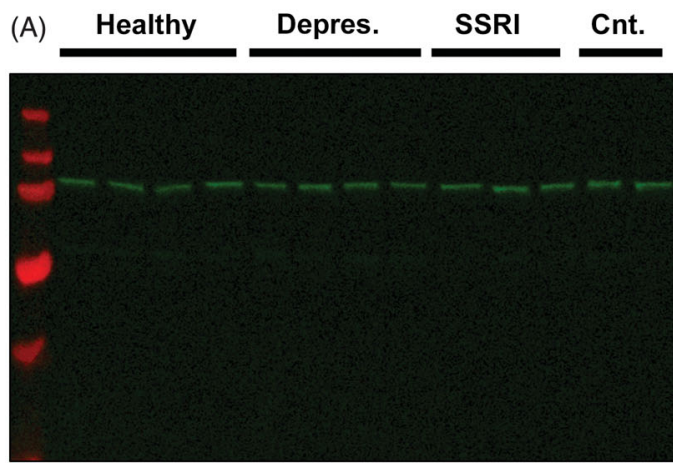

(C)

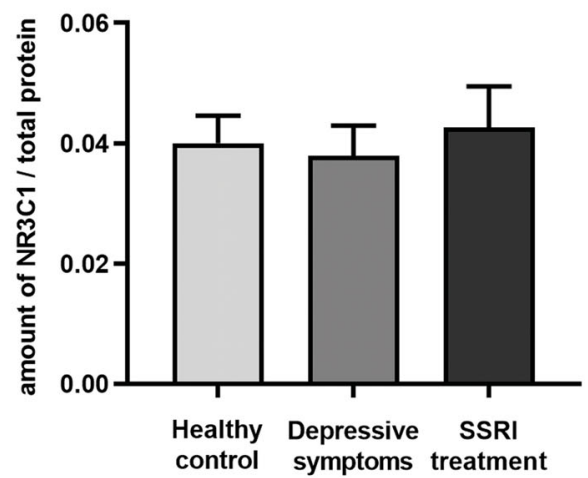

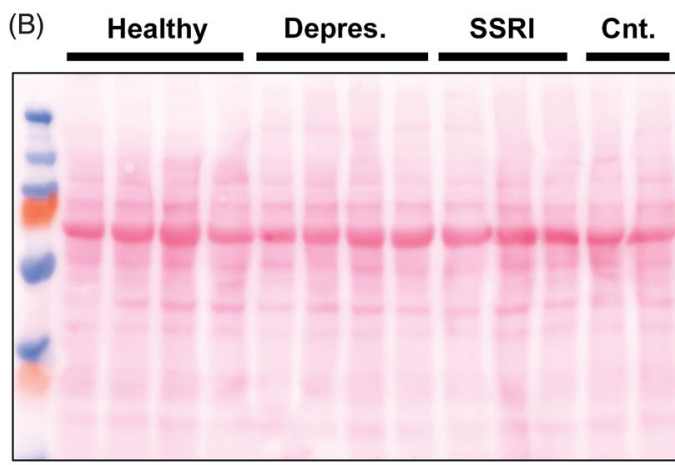

(D)

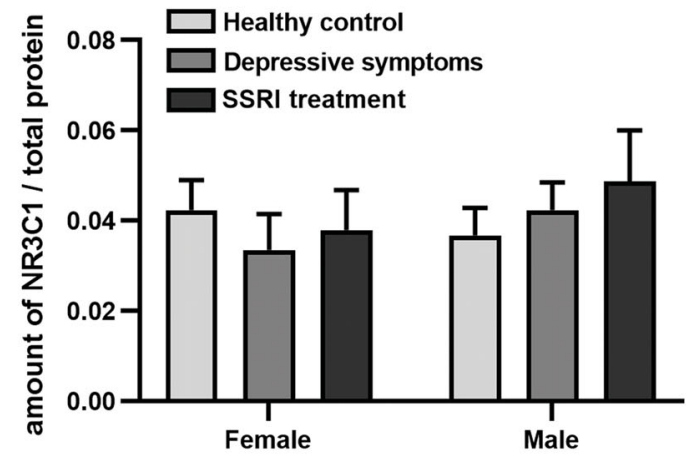

Figure 2. Glucocorticoid receptor protein in the placenta. (A, B) Representative Western blot of NR3C1 in placenta and corresponding Ponceau S stain; $20 \mu \mathrm{g}$ of placental samples from healthy controls (Healthy), women with depressive symptoms (Depres.), and women with SSRI treatment (SSRI) were loaded on each Western blot gel together with two control samples (Cnt.). The two control samples were loaded on all gels. In the far left lane, a molecular weight marker was loaded. NR3C1 was detected as a main band at $\sim 100 \mathrm{kDa}$; a weaker band was detected between 55 and $75 \mathrm{kDa}$. (C) Quantification of placental NR3C1 ( $100 \mathrm{kDa}$ band) separated into groups (Healthy control, Depressive symptoms, and SSRI treatment). Amount of NR3C1 was adjusted for total protein. $n=14-17 /$ group; $p>0.05$, one-way ANOVA. (D) Foetal sex and placental NR3C1 protein levels. $n=6-10 /$ group; $p>0.05$, one-way ANOVA. Data in graphs are presented as mean \pm SEM.

male foetuses (mean NR3C1/total protein levels $0.042 \pm 0.004$ versus $0.038 \pm 0.004 ; n=20-25 /$ group, $p>0.05, t$ test).

\section{Placental glucocorticoid receptor DNA binding activity}

DNA binding activity of the glucocorticoid receptor was detected in all 45 placentas investigated. There was no difference in glucocorticoid receptor activity between the three groups of women (healthy controls, depressive symptoms, and SSRI treatment; Figure 3(A)). Further, there was no difference in activation of the glucocorticoid receptor relating to foetal sex, neither when comparing placentas from healthy controls, depressive symptoms, and SSRI treatment (Figure $3(B)$ ), nor when comparing placentas from female versus male foetuses (median GR activation $0.057 \quad[95 \% \mathrm{Cl}$ 0.050-0.083] versus 0.074 [95\% Cl 0.067-0.107]; $n=20-25$ / group, $p>0.05$, Mann-Whitney $U$ test).

\section{Discussion}

In this study, we show that maternal depressive symptoms or use of SSRIs during pregnancy do not affect placental glucocorticoid receptor protein levels. Our finding contrasts with some previous reports describing an association between maternal prenatal stress and higher placental glucocorticoid receptor mRNA levels.
Maternal depressive symptoms or SSRI treatment affects placental RNA levels of multiple genes $(22,23)$. SSRIs can also influence the function of placental cells in vitro (24-26). These studies clearly demonstrate that such circumstances (maternal depression and SSRI treatment) affect the placenta. What factors are causative of such alterations need to be determined. However, several differences in circulating factors have been reported with maternal depression or SSRI treatment $(27-30)$. It is possible that one or more of these factors could alter placental RNA and protein levels, including the glucocorticoid receptor.

The human placenta expresses several isoforms of the glucocorticoid receptor (13). For this study, we used an antibody which detects both NR3C $1 \alpha$ and NR3C $1 \beta$ isoforms of the glucocorticoid receptor. In our Western blot analysis, one main band for the glucocorticoid receptor isoform was observed. This band likely consists of full-length glucocorticoid receptor $\alpha$ and $\beta$. Detecting both isoforms together might be considered a limitation in the current study. However, it is in accordance with many previous studies focussing on placental RNA levels of NR3C1 (14-16,23,31-34). Furthermore, a strong positive correlation between total $N R 3 C 1$ and $N R 3 C 1 \alpha$ mRNA levels has been reported, a relationship also observed to a lesser extent for $N R 3 C 1 \beta$ levels (17). This suggests that total glucocorticoid receptor levels are informative.

We did not observe an effect of maternal SSRI treatment upon placental glucocorticoid receptor levels. This finding is 

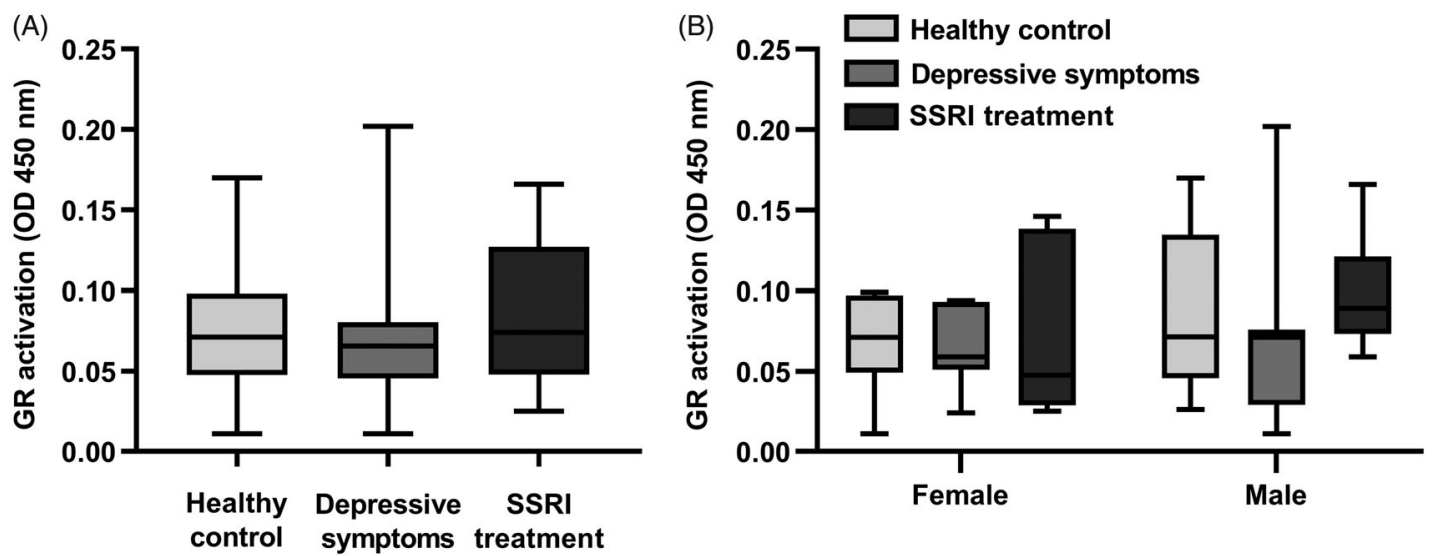

Figure 3. Placental glucocorticoid receptor activity. Activity of the glucocorticoid receptor measured in placental nuclear isolates by DNA binding capacity. (A) Glucocorticoid receptor activity in the three groups of women (Healthy control, Depressive symptoms, and SSRI treatment). $n=14-17 / g r o u p ; p>0.05$, Kruskal-Wallis. (B) Foetal sex and placental glucocorticoid receptor activation. $n=6-10 /$ group, $p>0.05$, Kruskal-Wallis. Data in graphs are presented as median, interquartile range, and $95 \%$ confidence interval.

in accordance with a previous study investigating RNA levels by microarray (23). Olivier and co-workers did, however, show that maternal SSRI treatment can affect the placenta, as genes relating to for instance cellular function and maintenance were differentially expressed (23). This suggests that, although SSRIs may have an impact on the placenta, its capacity to respond to glucocorticoids remains.

In this study, we found no effect of maternal depressive symptoms upon placental glucocorticoid receptor levels. Our finding is in accordance with a study by St-Pierre and coworkers, which did not observe an association between maternal depressive symptoms and placental NR3C1 mRNA levels (17). However, several other studies have suggested that maternal depressive symptoms $(15,16)$ or high perceived stress (14) affect placental glucocorticoid receptor mRNA levels. There may be several possible causes for these divergent results. First, the timing of experienced stress may influence effects on the glucocorticoid receptor. That is, if stress occurs in early, middle, or late pregnancy. Capron (15) estimated depressive symptoms the day before delivery, whereas in our study depressive symptoms were measured at 17 and 32 weeks gestation. Second, degree of stress may also affect the placental glucocorticoid receptor. A continuous low-grade stress may have different effects than a sudden, very stressful event. Finally, the type of stress experienced may also have an impact. Maternal stress can be estimated with a range of different tools, such as EPDS [current study and $(15,17)$ ], Centre for Epidemiologic Studies-Depression Scale (16), perceived high stress (14), and experience of a natural disaster (17). Therefore, maternal stress can be viewed as an umbrella term capturing a range of states that may or may not affect cellular signalling in the placenta.

Multiple types of stress experienced by the pregnant mother and the effects upon placental glucocorticoid receptor have been investigated. Some stresses appear to affect placenta from female and male foetuses differently. The stress of experiencing a natural disaster during pregnancy reduces glucocorticoid receptor RNA levels in placentas from male foetuses but not female foetuses (17), whereas high perceived emotional distress in the mother increases $N R 3 C 1 \alpha$
RNA levels in placentas from female but not male foetuses (18). Furthermore, Mina and co-workers reported that the levels of $N R 3 C 1 \alpha$ mRNA differ between placentas from female and male foetuses (18). We could not confirm such findings in our study. Neither the response to maternal depressive symptoms and SSRI treatment, nor overall glucocorticoid receptor levels differed depending on foetal sex in our cohort.

Another factor suggested as influencing how the placenta responds to stress is ethnicity. In a study by Capron and coworkers, maternal depressive symptoms were associated with increased placental NR3C1 RNA levels but only in Caucasian mothers (15). In our study, we did not observe such an association in this cohort of Scandinavian mothers.

It is well established that glucocorticoids are very important for adequate foetal development, but also that excess exposure can have potentially harmful effects, such as growth restriction (35). Glucocorticoids exert numerous effects on placenta, including influence of placental development, regulating placental nutrient transport and release of hormones (36). We report that protein levels of glucocorticoid receptor are unchanged for maternal depressive symptoms or SSRI treatment. Therefore, the placentas retain their capacity to respond to glucocorticoids. This observation is further supported by a similar level of glucocorticoid receptor activation, independent of maternal depressive symptoms or SSRI treatment. An altered sensitivity to glucocorticoids could have major effects on placental function, and subsequently the intrauterine environment, as glucocorticoids can regulate a substantial number of genes in our genome (35).

In conclusion, maternal depression and SSRI treatment do not affect glucocorticoid receptor protein levels or activity in placenta. Further research is needed for confirmation of the effects of prenatal stress upon placental biological mechanisms, as well as additional effects upon offspring.

\section{Acknowledgements}

The authors are grateful to all BASIC study participants and staff at Akademiska University Hospital delivery unit for sample collection. 


\section{Disclosure statement}

A.S. occasionally serves as an invited speaker at scientific meetings for Ferring Pharmaceuticals. I.S.P. occasionally serves on advisory boards or act as invited speaker at scientific meetings for MSD, Bayer Health Care, Peptonics, Shire/Takeda, and Lundbeck A/S. Å.E., A.H., M.H., T.K.K., and S.L. have no conflicts of interests to declare.

\section{Funding}

This study was supported by grants from the Swedish Research Council [VR:521-2013-2339 and VR:523-2014-2342]; Födelsefonden; and Lions.

\section{Notes on contributors}

Åsa Edvinsson, $\mathrm{PhD}$, is a postdoc at Uppsala University. She received her Master of Medical Science, Biomedicine and her PhD from Uppsala University. Her doctoral thesis focused on inflammation, placenta, and peripartum depression.

Angela Hoyer, Msc, is a research assistant at Karolinska Institutet in the field of asthma research in children. She received her Master Degree in Molecular Medicine from Uppsala University, and her Bachelor Degree from Erlangen University, Germany.

Malin Hansson, MD, works as a doctor at Hudiksvall Hospital, Sweden. She received her medical degree from Uppsala University.

Theodora Kunovac Kallak, PhD, is a researcher at Uppsala University. Her research activities cover genitourinary symptoms of menopause, infertility, gynecological cancers, maternal health during pregnancy and the effect of the future health of the offspring.

Inger Sundström-Poromaa, MD, PhD, is a Professor of Obstetrics and Gynecology at Uppsala University. Her research interests include adverse mood effects of hormonal contraception, premenstrual dysphoric disorder, peripartum depression, and brain imaging.

Alkistis Skalkidou, MD, PhD, is a Professor of Obstetrics and Gynecology at Uppsala University, senior consultant at Akademiska University Hospital, and serves as President of the Gynecologic Endocrinology group of the Swedish Society of Obstetricians and Gynecologists. Her research activities include peripartum depression and its effects on the offspring, ultrasound pregnancy dating, and studies on vulvodynia.

Susanne Lager, $\mathrm{PhD}$, is a researcher and a docent in Experimental Obstetrics and Gynecology at Uppsala University. Her research interests include pregnancy complications, infections, maternal substance abuse, and placenta.

\section{ORCID}

Åsa Edvinsson (iD http://orcid.org/0000-0002-6246-7218 Theodora Kunovac Kallak (D) http://orcid.org/0000-0002-2112-8674 Inger Sundström-Poromaa (iD http://orcid.org/0000-0002-2491-2042 Alkistis Skalkidou (ID) http://orcid.org/0000-0002-4935-7532 Susanne Lager (iD http://orcid.org/0000-0003-3556-065X

\section{References}

1. Woody CA, Ferrari AJ, Siskind DJ, Whiteford HA, Harris MG. A systematic review and meta-regression of the prevalence and incidence of perinatal depression. J Affect Disord. 2017;219: 86-92.

2. Andersson $L$, Sundström-Poromaa $I$, Bixo $M$, Wulff $M$, Bondestam $\mathrm{K}$, Åström M. Point prevalence of psychiatric disorders during the second trimester of pregnancy: a population-based study. Am J Obstet Gynecol. 2003;189:148-54.

3. Melville JL, Gavin A, Guo Y, Fan MY, Katon WJ. Depressive disorders during pregnancy: prevalence and risk factors in a large urban sample. Obstet Gynecol. 2010;116:1064-70.

4. Charlton RA, Jordan S, Pierini A, Garne E, Neville AJ, Hansen AV, et al. Selective serotonin reuptake inhibitor prescribing before, during and after pregnancy: a population-based study in six European regions. BJOG. 2015;122:1010-20.

5. Huybrechts KF, Palmsten K, Mogun H, Kowal M, Avorn J, Setoguchi-Iwata $\mathrm{S}$, et al. National trends in antidepressant medication treatment among publicly insured pregnant women. Gen Hosp Psychiatry. 2013;35:265-71.

6. Grote NK, Bridge JA, Gavin AR, Melville JL, lyengar S, Katon WJ. A meta-analysis of depression during pregnancy and the risk of preterm birth, low birth weight, and intrauterine growth restriction. Arch Gen Psychiatry. 2010;67:1012-24.

7. Kallen B. Neonate characteristics after maternal use of antidepressants in late pregnancy. Arch Pediatr Adolesc Med 2004;158: 312-6.

8. Wen SW, Yang Q, Garner P, Fraser W, Olatunbosun O, Nimrod C, et al. Selective serotonin reuptake inhibitors and adverse pregnancy outcomes. Am J Obstet Gynecol. 2006;194:961-6.

9. El Marroun H, Jaddoe VW, Hudziak JJ, Roza SJ, Steegers EA, Hofman $A$, et al. Maternal use of selective serotonin reuptake inhibitors, fetal growth, and risk of adverse birth outcomes. Arch Gen Psychiatry. 2012;69:706-14.

10. Cao-Lei L, de Rooij SR, King S, Matthews SG, Metz GAS, Roseboom TJ, et al. Prenatal stress and epigenetics. Neurosci Biobehav Rev. 2017. doi:10.1016/j.neubiorev.2017.05.016

11. Stirrat LI, Sengers BG, Norman JE, Homer NZM, Andrew R, Lewis RM, et al. Transfer and metabolism of cortisol by the isolated perfused human placenta. Clin Endocrinol Metab. 2018;103: 640-8.

12. Scheschowitsch K, Leite JA, Assreuy J. New insights in glucocorticoid receptor signaling-more than just a ligand-binding receptor. Front Endocrinol (Lausanne). 2017;8:16.

13. Saif Z, Hodyl NA, Stark MJ, Fuller PJ, Cole T, Lu N, et al. Expression of eight glucocorticoid receptor isoforms in the human preterm placenta vary with fetal sex and birthweight. Placenta. 2015;36: 723-30.

14. Togher KL, Treacy E, O'Keeffe GW, Kenny LC. Maternal distress in late pregnancy alters obstetric outcomes and the expression of genes important for placental glucocorticoid signalling. Psychiatry Res. 2017;255:17-26.

15. Capron LE, Ramchandani PG, Glover V. Maternal prenatal stress and placental gene expression of NR3C1 and HSD11B2: the effects of maternal ethnicity. Psychoneuroendocrinology 2018;87: 166-72.

16. Reynolds RM, Pesonen A-K, O'Reilly JR, Tuovinen S, Lahti M, Kajantie $\mathrm{E}$, et al. Maternal depressive symptoms throughout pregnancy are associated with increased placental glucocorticoid sensitivity. Psychol Med. 2015;45:2023-30.

17. St-Pierre J, Laplante DP, Elgbeili G, Dawson PA, Kildea S, King S, et al. Natural disaster-related prenatal maternal stress is associated with alterations in placental glucocorticoid system: The QF2011 Queensland Flood Study. Psychoneuroendocrinology. 2018;94: 38-48.

18. Mina TH, Raikkonen K, Riley SC, Norman JE, Reynolds RM Maternal distress associates with placental genes regulating fetal glucocorticoid exposure and IGF2: role of obesity and sex. Psychoneuroendocrinology. 2015;59:112-22.

19. Axfors C, Brann E, Henriksson HE, Hellgren C, Kunovac Kallak $T$, Fransson E, et al. Cohort profile: the Biology, Affect, Stress, Imaging and Cognition (BASIC) study on perinatal depression in a population-based Swedish cohort. BMJ Open. 2019;9:e031514.

20. Cox JL, Holden JM, Sagovsky R. Detection of postnatal depression. Development of the 10-item Edinburgh Postnatal Depression Scale. Br J Psychiatry. 1987;150:782-6. 
21. Lanoix D, St-Pierre J, Lacasse AA, Viau M, Lafond J, Vaillancourt C. Stability of reference proteins in human placenta: general protein stains are the benchmark. Placenta 2012;33:151-6.

22. Kaihola $\mathrm{H}$, Olivier J, Poromaa IS, Akerud $\mathrm{H}$. The effect of antenatal depression and selective serotonin reuptake inhibitor treatment on nerve growth factor signaling in human placenta. PLoS One. 2015;10:e0116459.

23. Olivier JD, Akerud H, Skalkidou A, Kaihola H. Sundstrom-Poromaa I. The effects of antenatal depression and antidepressant treatment on placental gene expression. Front Cell Neurosci. 2014;8:

24. Clabault H, Flipo D, Guibourdenche J, Fournier T, Sanderson JT, Vaillancourt C. Effects of selective serotonin-reuptake inhibitors (SSRIs) on human villous trophoblasts syncytialization. Toxicol Appl Pharmacol. 2018;349:8-20.

25. Arumugasaamy N, Gudelsky A, Hurley-Novatny A, Kim PCW, Fisher JP. Model placental barrier phenotypic response to fluoxetine and sertraline: a comparative study. Adv Healthcare Mater. 2019;8: e1900476.

26. Clabault H, Cohen M, Vaillancourt C, Sanderson JT. Effects of selective serotonin-reuptake inhibitors (SSRIs) in JEG-3 and HIPEC cell models of the extravillous trophoblast. Placenta. 2018;72-73: 62-73.

27. Edvinsson A, Brann $E$, Hellgren C, Freyhult $E$, White $R$, Kamali-Moghaddam $M$, et al. Lower inflammatory markers in women with antenatal depression brings the M1/M2 balance into focus from a new direction. Psychoneuroendocrinology. 2017;80: $15-25$.

28. Henriksson HE, Malavaki C, Brann E, Drainas V, Lager S, Iliadis SI, et al. Blood plasma metabolic profiling of pregnant women with antenatal depressive symptoms. Transl Psychiatry. 2019;9:204.
29. Hannerfors AK, Hellgren C, Schijven D, lliadis SI, Comasco E, Skalkidou $A$, et al. Treatment with serotonin reuptake inhibitors during pregnancy is associated with elevated corticotropinreleasing hormone levels. Psychoneuroendocrinology. 2015;58: 104-13.

30. Osborne LM, Yenokyan G, Fei K, Kraus T, Moran T, Monk C, et al. Innate immune activation and depressive and anxious symptoms across the peripartum: an exploratory study. Psychoneuroendocrinology. 2019;99:80-6.

31. Raikkonen K, O'Reilly JR, Pesonen AK, Kajantie E, Villa P, Laivuori $\mathrm{H}$, et al. Associations between maternal level of education and occupational status with placental glucocorticoid regeneration and sensitivity. Clin Endocrinol. 2014;81:175-82.

32. Raikkonen K, Pesonen AK, O'Reilly JR, Tuovinen S, Lahti M, Kajantie $E$, et al. Maternal depressive symptoms during pregnancy, placental expression of genes regulating glucocorticoid and serotonin function and infant regulatory behaviors. Psychol Med. 2015;45:3217-26.

33. Deyssenroth MA, Li Q, Lacasana M, Nomura Y, Marsit C, Chen J. Expression of placental regulatory genes is associated with fetal growth. J Perinat Med. 2017;45:887-93.

34. Zhang W, Finik J, Dana K, Glover V, Ham J, Nomura Y. Prenatal depression and infant temperament: the moderating role of placental gene expression. Infancy. 2018;23:211-31.

35. Clifton VL, Cuffe J, Moritz KM, Cole TJ, Fuller PJ, Lu NZ, et al. Review: The role of multiple placental glucocorticoid receptor isoforms in adapting to the maternal environment and regulating fetal growth. Placenta. 2017;54:24-9.

36. Fowden AL, Forhead AJ, Sferruzzi-Perri AN, Burton GJ, Vaughan OR. Review: Endocrine regulation of placental phenotype. Placenta. 2015;36:S50-S9. 